\title{
Impact of Donor and Recipient Cytokine Genotypes on Renal Allograft Outcome
}

\author{
D. Ligeiro, M.R. Sancho, A. Papoila, A.M. Barradinhas, A. Almeida, S. Calão, D. Machado, F. Nolasco, \\ J. Guerra, M.J. Sampaio, and H. Trindade
}

\begin{abstract}
Allelic differences in gene promoter or codifying regions have been described to affect regulation of gene expression, consequently increasing or decreasing cytokine production and signal transduction responses to a given stimulus. This observation has been reported for interleukin (IL)-10 (-1082 A/G; $-819 /-592 \mathrm{CT} / \mathrm{CA})$, transforming growth factor (TGF)- $\beta$ (codon $10 \mathrm{C} / \mathrm{T}$, codon $25 \mathrm{G} / \mathrm{C}$ ), tumor necrosis factor (TNF)- $\alpha$ (-308 G/A), TNF- $\beta(+252 \mathrm{~A} / \mathrm{G})$, interferon (IFN)- $\gamma(+874 \mathrm{~T} / \mathrm{A})$, IL-6 $(-174 \mathrm{G} / \mathrm{C})$, and IL-4R $\alpha$ $(+1902 \mathrm{G} / \mathrm{A})$. To evaluate the influence of these cytokine genotypes on the development of acute or chronic rejection, we correlated the genotypes of both kidney graft recipients and cadaver donors with the clinical outcome. Kidney recipients had 5 years follow-up, at least 2 HLA-DRB compatibilities, and a maximum of $25 \%$ anti-HLA pretransplantation sensitization. The clinical outcomes were grouped as follows: stable functioning graft (NR, $\mathrm{n}=35)$; acute rejection episodes (AR, $\mathrm{n}=31$ ); and chronic rejection $(\mathrm{CR}, \mathrm{n}=31)$. The cytokine genotype polymorphisms were defined using PCR-SSP typing. A statistical analysis showed a significant prevalence of recipient IL-10 -819/-592 genotype among CR individuals; whereas among donors, the TGF- $\beta$ codon 10 CT genotype was significantly associated with the AR cohort and the IL-6 -174 CC genotype with CR. Other albeit not significant observations included a strong predisposition of recipient TGF- $\beta$ codon 10 CT genotype with CR, and TNF- $\beta 252$ AA with AR. A low frequency of TNF- $\alpha$ -308 AA genotype also was observed among recipients and donors who showed poor allograft outcomes.
\end{abstract}

$\mathrm{D}$ ESPITE the advances in immunosuppressive therapy, acute and chronic rejection remain major causes of long-term allograft failure. After kidney transplantation, the presence of non-self antigens induces activation of antigen specific $\mathrm{T}$ and $\mathrm{B}$ lymphocytes. This results in a cascade of small soluble peptide mediators, called cytokines, released by graft infiltrating and local cells. Cytokines, by binding to high affinity receptors on target cells, induce biochemical signals that regulate the immune system by influencing cellular activation, differentiation, and function. ${ }^{1}$ These changes are dependent on cytokine levels; therefore, expression of these genes is under stringent control. Allelic differences in promoter or codifying regions have been described to regulate gene expression, consequently increasing or decreasing cytokine production or signal transduction to a single stimuli. ${ }^{2,3}$ This observation has been reported for interleukin (IL)-10 $(-1082 \mathrm{~A} / \mathrm{G}$, $-819 /-592 \mathrm{CT} / \mathrm{CA}$ ), transforming growth factor (TGF) $\beta$ (codon $10 \mathrm{C} / \mathrm{T}$, codon $25 \mathrm{G} / \mathrm{C}$ ), tumor necrosis factor (TNF)- $\alpha(-308$ G/A), TNF- $\beta(+252 \mathrm{~A} / \mathrm{G})$, interferon (IFN)- $\gamma(+874$ T/A), IL-6 (-174 G/C), and IL-4R $\alpha(+1902$ $\mathrm{G} / \mathrm{A}){ }^{2,3}$ To evaluate the influence of cytokine genotypes on the development of acute or chronic rejection, genotype

From the Centro de Histocompatibilidade do Sul, Lisbon, Portugal (D.L., M.R.S., A.M.B., A.A., S.C., H.T.), Department of Biomathematics of Medical Sciences School, Lisbon, Portugal (A.P.), Hospital St Cruz, Lisbon, Portugal (D.M.), Hospital Curry Cabral, Lisbon, Portugal (F.N.), Hospital St Maria, Lisbon, Portugal (J.G.), and Hospital Cruz Vermelha, Lisbon, Portugal (M.J.S.).

This study was awarded a grant by the Funding Committee for Health Care Investigation, Ministry of Health P.I. $n^{\circ} 1 / 01$.

Address reprint requests to Helder Trindade, MD, PhD, Centro de Histocompatibilidade do Sul, Campo de Santana 1301169 056 Lisbon, Portugal. E-mail: helder.trindade@chsul.pt

0041-1345/04/\$-see front matter doi:10.1016/j.transproceed.2004.03.082 
Table 1. Rate (\%) of Cytokine Polymorphism Genotypes in Recipients and Donors With Stable Graft (Group NR), Grafts Developing AR (Group AR), and Grafts Developing CR (Group CR)

\begin{tabular}{|c|c|c|c|c|c|c|c|}
\hline & & \multicolumn{3}{|c|}{ Recipient } & \multicolumn{3}{|c|}{ Donor } \\
\hline & & $\begin{array}{c}\text { Group } \\
\text { NR } \\
(n=35)\end{array}$ & $\begin{array}{c}\text { Group } \\
\text { AR } \\
(n=31)\end{array}$ & $\begin{array}{c}\text { Group } \\
\text { CR } \\
(n=31)\end{array}$ & $\begin{array}{c}\text { Group } \\
\text { NR } \\
(n=35)\end{array}$ & $\begin{array}{c}\text { Group } \\
\text { AR } \\
(n=31)\end{array}$ & $\begin{array}{c}\text { Group } \\
\text { CR } \\
(n=31)\end{array}$ \\
\hline \multirow[t]{3}{*}{ IL-6 (-174) } & GG & 48.6 & 48.4 & 38.7 & 45.7 & 61.3 & 45.2 \\
\hline & $\mathrm{GC}$ & 42.9 & 45.2 & 45.2 & 48.6 & 32.3 & 29 \\
\hline & CC & 8.6 & 6.5 & 16.1 & 5.7 & 6.5 & $25.8^{\star}$ \\
\hline \multirow[t]{3}{*}{ IL-10 (-1082) } & GG & 14.3 & 12.9 & 16.1 & 25.7 & 22.6 & 19.4 \\
\hline & GA & 54.3 & 58.1 & 54.8 & 40 & 29 & 48.4 \\
\hline & $\mathrm{AA}$ & 31.4 & 29 & 29 & 34.3 & 48.4 & 32.3 \\
\hline \multirow[t]{3}{*}{ IL-10 (-819/-592) } & $\mathrm{T} / \mathrm{T} \mathrm{A} / \mathrm{A}$ & 6.6 & 9.7 & 0 & 2.9 & 9.7 & 6.5 \\
\hline & $\mathrm{C} / \mathrm{T} \mathrm{C} / \mathrm{A}$ & 34.3 & 41.9 & $67.7^{\star}$ & 51.4 & 41.9 & 48.4 \\
\hline & $\mathrm{C} / \mathrm{C} \mathrm{C} / \mathrm{C}$ & 57.1 & 48.4 & 32.3 & 45.7 & 48.4 & 51.6 \\
\hline \multirow[t]{3}{*}{ TNF- $\alpha(-308)$} & $\mathrm{GG}$ & 74.3 & 93.5 & 74.2 & 80 & 83.6 & 71 \\
\hline & GA & 25.7 & 3.2 & 22.6 & 20 & 16.1 & 19.4 \\
\hline & $\mathrm{AA}$ & 0 & $3.2^{\ddagger}$ & $3.2^{\ddagger}$ & 0 & 0 & $9.7^{\ddagger}$ \\
\hline \multirow[t]{3}{*}{$\mathrm{TNF}-\beta(+252)$} & $\mathrm{AA}$ & 2.9 & 0 & 9.7 & 11.4 & 9.7 & 12.9 \\
\hline & $A G$ & 57.1 & 35.5 & 64.5 & 31.4 & 29 & 32.3 \\
\hline & $\mathrm{GG}$ & 40 & $64.5^{\dagger}$ & 41.9 & 57.1 & 61.3 & 54.8 \\
\hline \multirow[t]{3}{*}{ TGF- $\beta$ (codon 10) } & $\mathrm{CC}$ & 17.1 & 22.6 & 19.4 & 20 & 12.9 & 12.9 \\
\hline & CT & 42.9 & 38.7 & $61.3^{\dagger}$ & 40 & $71^{*}$ & 58.1 \\
\hline & $\mathrm{TT}$ & 40 & 38.7 & 19.4 & 40 & 16.1 & 29 \\
\hline \multirow[t]{3}{*}{ TGF- $\beta$ (codon 25) } & GG & 82.9 & 83.9 & 93.5 & 85.7 & 80.6 & 83.9 \\
\hline & $\mathrm{GC}$ & 14.3 & 16.1 & 3.2 & 14.3 & 19.4 & 16.1 \\
\hline & $\mathrm{CC}$ & 2.9 & 0 & 3.2 & 0 & 0 & 0 \\
\hline \multirow[t]{3}{*}{ IFN- $\gamma(+874)$} & $\mathrm{TT}$ & 31.4 & 19.4 & 9.7 & 20 & 12.9 & 12.9 \\
\hline & AT & 51.4 & 64.5 & 67.7 & 51.4 & 58.1 & 64.5 \\
\hline & $\mathrm{AA}$ & 17.1 & 16.1 & 22.6 & 28.6 & 29 & 22.6 \\
\hline \multirow[t]{3}{*}{ IL-4R $\alpha(+1902)$} & GG & 68.6 & 54.8 & 54.8 & 60 & 58.1 & 67.7 \\
\hline & GA & 25.7 & 35.5 & 38.7 & 37.1 & 29 & 25.8 \\
\hline & $\mathrm{AA}$ & 5.7 & 9.7 & 6.5 & 2.9 & 12.9 & 6.5 \\
\hline
\end{tabular}

*Significant cytokine genotypes of recipients and donors associated with AR or CR comparing stable graft frequencies $(P<.05)$.

${ }^{\dagger}$ Genotype disturbance frequencies that although nonsignificant clearly prevail in the problematic renal allografts.

¥High production TNF- $\alpha-308$ A/A genotype of both donors and recipients was only found in poor outcome transplants $(P$ was nonsignificant).

frequencies were compared among a population of renal transplant recipients. In addition, because cytokines derived from the graft may influence the local immune environment, donor genotypes also were examined.

\section{MATERIALS AND METHODS}

Cytokine genotypes were identified using polymerase chain reactions (PCR) and sequence specific primers (SSP) as described elsewhere. ${ }^{4,5}$ Genomic DNA was extracted from frozen buffy coats or spleen cells of cadaver donors using a "salting-out" procedure.

To decrease the impact of known deleterious effects on graft evolution donor-recipient pairs were chosen without prior antiHLA sensitization and more than 2 HLA-DR compatibilities. (maximum $=25 \%$ anti- class I). All patients followed an immunosuppressive therapy based on cyclosporine (CsA), azathioprine, and corticosteroids. Nonimmune risk factors, such as obesity and diabetes, led to exclusion from the study.

Patients were grouped according to clinical outcomes: nonrejectors $(\mathrm{NR}, \mathrm{n}=35)$, acute rejection episodes $(\mathrm{AR}, \mathrm{n}=31)$; and chronic rejection processes $(\mathrm{CR}, \mathrm{n}=31)$. Patients with at least 1 rejection crisis within the first posttransplantation month, proven using renal biopsy according to the Banff 97 revised criteria, ${ }^{6}$ were included as AR. CR patients showed a sustained increase in creatinine levels over time, a diagnosis that was confirmed using histological assessment of renal biopsy specimens. NR were patients with stable graft function for more than 3 years who did not have an AR history.

Univariate statistical analysis compared ages of the 3 groups with the nonparametric Kruskal-Wallis test. Comparisons of cytokine genotype rates were performed using a Chi-square test or a Fisher exact test.

\section{RESULTS}

To evaluate the influence of cytokine genotypes on the development of $\mathrm{AR}$ or $\mathrm{CR}$, genotype frequencies in recipients and cadaver kidney donors were stratified according to the clinical outcome.

As shown in Table 1, statistical analysis showed a statistically significant prevalence of recipient IL-10 -819/-592 CT/CA genotype among CR individuals $(P=.01)$, whereas donor TGF- $\beta$ codon $10 \mathrm{C} / \mathrm{T}$ genotype was significantly higher among AR grafts $(P=.012)$ and IL-6 -174 C/C genotype among $\mathrm{CR}$ patients $(P<.05)$. Moreover, although nonsignificant, we observed a strong trend of recipient TGF- $\beta$ codon $10 \mathrm{C} / \mathrm{T}$ genotype with $\mathrm{CR}$ and TNF- $\beta$ $252 \mathrm{~A} / \mathrm{A}$ with $\mathrm{AR}$ ( $P$ was nonsignificant). The analysis of TNF- $\alpha$ genotype frequencies suggested that the less com- 
mon $-308 \mathrm{~A} / \mathrm{A}$ high production genotype only was found in recipients and donors of poor outcome kidney transplants ( $P$ was nonsignificant).

\section{DISCUSSION}

$\mathrm{AR}$ and $\mathrm{CR}$ of allogeneic transplants are complex processes influenced by many immune and nonimmune factors. ${ }^{1}$ Among the population evaluated herein, there was no association between HLA class I mismatches and the allograft course, but a detrimental association of clinical outcome of transplants with donor age was present albeit not-significant $(\mathrm{p}>0.05)$.

Previous work reported that the IL-10 -1082 G/A substitution correlates with poor renal allograft outcome. ${ }^{2} \mathrm{We}$ did not confirm this finding, but did observe a significant association between IL-10 -819/-592 heterozygous recipients and CR. Therefore, various nucleotide forms of the IL-10 gene promoting region influence regulation of gene expression. Our study also noted a correlation between donor TGF- $\beta$ codon 10 heterozygous genotype and an AR crisis. Recipients of the same genotype showed a marked elevation of CR injured grafts, albeit nonsignificant. This observation conforms with the biological activity of TGF- $\beta$ to promote fibrinogenesis, a clear sign of CR. Expression of this cytokine is up-regulated by $\mathrm{CsA},{ }^{7}$ a mechanism that, when associated with the heterozygous gene, could be responsible for the detrimental outcome of renal allografts by $\mathrm{AR}$, if the donor has the 2 variants that codify polymorphism, or by CR, if the recipient has the 2 variants.

IL-6, a pleotropic cytokine mediator of the acute phase response, was reported in another study ${ }^{5}$ as an impact factor predictive of the incidence and severity of AR after renal transplantation when donor genotype was IL-6 -174 CC. This effect was independent of other major genetic determinants of AR, even donor-recipient HLA-DR matching. ${ }^{5}$ In our study the probed population was selected with full HLA-DR matching and we could not see the described association, but we did find a significant correlation between donor IL-6 -174 CC genotype and CR injured grafts. This genotype remains a strong donor factor predictive of allograft outcome.

The utility of cytokine genotype profiles to predict graft immune outcome is controversial. The conflicting results may in part, be due to variables among transplant centers, such as immunotherapy regimens and the different procedures for rejection diagnosis (proven or not using biopsy). ${ }^{8}$ Furthermore, because the molecules encoded by these genes act in highly coordinated pathways, we can hardly expect to correlate a single gene variant with the entire immune reaction to a kidney transplant.

In this study we sought to assess the impact of donors and recipient, gene variants for the development of AR and CR in kidney transplants. Like in other studies, we did observe associations between clinical outcome and gene variants. $^{2,5,9}$ Nevertheless, these were not clear enough to identify high-risk patients or direct immunosuppressive regimens. To elucidate the consequences of gene variants in allograft immunological outcomes, further efforts must be made to increase sample size and include a multivariate analysis in the statistical study.

\section{REFERENCES}

1. Paul WE, Seder RA: Cell 76:241, 1994

2. Hutchinson IV, Turner D: Sankaran D, et al: Transplant Proc 30:3991, 1998

3. Hackstein H, Klüter H, Fricke L, et al: Tissue Antigens 54:573, 1998

4. Perrey C, Turner SJ, Pravica V, et al: Transplant Immunol 7:127, 1999

5. Marshall S, Mclaren A, Mckinney E, et al: Transplantation 71:469, 2001

6. Racusen LR, Solez K, Colvin RB, et al: Kidney Int 55:713, 1999

7. Khanna A, Cairns VR, Becker CG, et al: Transplantation 67:882, 1999

8. Alkalin E, Murphy B: Curr Opin. Immunol 13:572, 2001

9. Poli F, Boschiero L, Giannoni F, et al: Cytokine 12:1778, 2000 